\title{
Review \\ Standardized Outcomes Measures in Physical Therapy Practice for Treatment and Rehabilitation of Cerebral PALSY: A Systematic Review
}

\author{
Maria Dolores Apolo-Arenas ${ }^{1}\left(\mathbb{D}\right.$, Aline Ferreira de Araújo Jerônimo ${ }^{2} \mathbb{D}$, Alejandro Caña-Pino ${ }^{1}(\mathbb{D}$, \\ Orlando Fernandes ${ }^{2,3}\left(\right.$, , Joana Alegrete ${ }^{2}$ and Jose Alberto Parraca ${ }^{2,3, *(1)}$ \\ 1 Departamento Terapéutica Médico Quirúrgica, Facultad de Medicina, Universidad de Extremadura, \\ 06006 Badajoz, Spain; mdapolo@unex.es (M.D.A.-A.); alejandrocp@unex.es (A.C.-P.) \\ 2 Departamento de Desporto e Saúde, Escola de Saúde e Desenvolvimento Humano, Universidade de Évora, \\ 7004-516 Évora, Portugal; alinea.fje@gmail.com (A.F.d.A.J.); orlandoj@uevora.pt (O.F.); \\ joana.alegrete@fa.uevora.pt (J.A.) \\ 3 Comprehensive Health Research Centre (CHRC), Universidade de Évora, 7004-516 Évora, Portugal \\ * Correspondence: jparraca@uevora.pt
}

Citation: Apolo-Arenas, M.D.; Jerônimo, A.F.d.A.; Caña-Pino, A.; Fernandes, O.; Alegrete, J.; Parraca, J.A. Standardized Outcomes Measures in Physical Therapy Practice for Treatment and Rehabilitation of Cerebral PALSY: A Systematic Review. J. Pers. Med. 2021, 11,604. https://doi.org/10.3390/ jpm11070604

Academic Editors: Robert E. Akins and Pritmohinder S. Gill

Received: 18 March 2021

Accepted: 18 June 2021

Published: 26 June 2021

Publisher's Note: MDPI stays neutral with regard to jurisdictional claims in published maps and institutional affiliations.

Copyright: (c) 2021 by the authors. Licensee MDPI, Basel, Switzerland. This article is an open access article distributed under the terms and conditions of the Creative Commons Attribution (CC BY) license (https:// creativecommons.org/licenses/by/ $4.0 /)$.
Abstract: Cerebral palsy (CP) treatment includes physical therapy and various complementary therapies to the standard clinical treatment. However, there are not many reviews that focus on the methods used and evaluation procedures. This study aims to analyze which tools are most suitable for the evaluation and methodology of patients with CP treated with physical therapy. Following the PRISMA statement, through a PICOS strategy, PubMed/MEDLINE, Web of Science (WOS), Scopus, Science Direct, and Scielo were searched with the following terms: cerebral palsy AND (physical therapy modalities OR therapeutics) AND outcome assessment. The methodological quality of the RCTs was assessed with the Evidence Project risk of bias tool. Thirty-seven RCTs and six RCT protocols, comprising 1359 participants with different types of CP: spastic hemiplegia/paresis, spastic diplegia/paresis, and spastic CP, met the inclusion criteria, uncovering 21 variables measured through 77 different instruments and several interventions. The therapies most widely used in $\mathrm{CP}$ are gaming or technology-assisted therapies, aerobic training, hippotherapy, music therapy, gait training, and aquatic exercises. This study provides an overview of what the authors used in the neurorehabilitation field through procedure evaluation and checking the technological advance that began to be used.

Keywords: cerebral palsy; physical therapy; outcome assessment

\section{Introduction}

Cerebral palsy (CP) definition has been evolving throughout time. According to Rosembaum [1], "Cerebral palsy (CP) describes a group of permanent disorders of the development of movement and posture, causing activity limitation, that are attributed to nonprogressive disturbances that occurred in the developing fetal or infant brain. The motor disorders of CP are often accompanied by disturbances of sensation, perception, cognition, communication, and behavior, by epilepsy, and by secondary musculoskeletal problems".

According to Surveillance of Cerebral Palsy in Europe (SCPE), CP can be classified per motor impairment, covering spastic, dyskinetic, ataxic, nonclassifiable types, and distribution (unilateral or bilateral, depending on the involved brain side) [2]. Despite prenatal and other unknown causes representing most cases of $\mathrm{CP}$, premature birth constitutes the principal risk factor; when accounting for this, $10-15 \%$ of all CPs are postnatal [3]. The diagnosis starts with a medical history check to evaluate abnormal findings congruent with CP's symptoms. It is posteriorly confirmed through specific evaluation methods such as neuroimaging, standardized neurological, and standardized motor assessments [4]. 
As seen in $\mathrm{CP}$, impairments in motor function are often associated with communicative, cognitive, and perceptive problems that negatively influence educational [5] and vocational development [6].

The most important element of $\mathrm{CP}$ treatment is multifaceted improvement. The major role in this improvement is played by systematic and comprehensive motor rehabilitation, individually tailored to the patient [2]. The literature shows the positive effects of conventional physical therapy methodologies, and other multimodal complementary modalities approached from physical therapy, such as music therapy, hydrotherapy, or animal-assisted therapy (e.g., equine-assisted therapy) [7]. Although each patient presents a variety of functional disorders and treatment is multifactorial, the results of each treatment may vary [8]. Therefore, the assessment of the therapy outcomes is critical [8]; once accomplished, it validates the therapy or allows for replacement with one more reliable, making the treatment more effective in the long term [9].

Despite the availability of several instruments for CP's outcome analysis that reflect the variety of functional disorders and specific restrictions, the literature focuses on the benefits of interventions in CP [10]. Additionally, instruments and procedures used to characterize $\mathrm{CP}$ are challenging to choose because there are ample options with particular outcomes, which are not always present in the patients and sometimes require specific training. As a result, there is a need for systematic knowledge about the methods and procedures for evaluating the outcome of $\mathrm{CP}$ treatment. An incisive knowledge through the available method and procedures on $\mathrm{CP}$ assessment outcomes may contribute to the design of investigation that is focused on functional diversity patients, thus facilitating the choice of method and procedure.

Therefore, this study analyzes which tools are the most suitable to measure outcomes in CP patients treated with physical therapy, providing an overview of evaluation procedures used in different physical therapy modalities and determining if technological advance has begun to be implemented in the process.

\section{Methods}

This study followed the Preferred Reporting Items for Systematic Reviews and MetaAnalyses (PRISMA) statement.

\subsection{Eligibility Criteria}

The PICOS strategy was defined, in which (P) refers to people from 1 year old up to 50 years old, of any sex or ethnicity with a diagnosis of CP. Abbreviation (I) corresponds to physical therapy or any technique within physical therapy modalities; $(C)$ refers to a group with no intervention, comparing different interventions, or the same group before and after the intervention; $(\mathrm{O})$ corresponds to evaluation methods applied to analyze the outcomes related to physical capacities, functionality, and quality of life after intervention; and (S) indicates randomized control trials studies (RCT). The inclusion criteria were (a) articles observing evaluation methods applied for analysis of benefits obtained with physical therapy; (b) studies analyzing the results of an intervention plan and reporting the number of sessions; (c) available full-text articles in Spanish, English, or Portuguese; and (d) the last five-year time coverage, from 2016 to September 2020. Exclusion criteria were studies (a) about masticatory function, (b) with drug treatments or invasive procedures, (c) with individuals having CP associated with other neurological dysfunction, (d) with surgical interventions, and (e) with interventions focused on orthoses.

\subsection{Information Sources and Search Strategy}

A structured search strategy was developed using the Medical Subject Headings (MeSH) vocabulary. According to the strategy, in September 2020, we searched the following electronic databases: PubMed/MEDLINE, Web of Science (WOS), Scopus, Science Direct, and Scielo. The MeSH terms used were cerebral palsy AND (physical therapy modalities OR therapeutics) AND outcome assessment. In addition, for the Pubmed 
database, we applied two filters: "randomized control trial" and " 5 years". In the other databases selected, we applied a time-related filter (last five years); this time interval for eligible studies was defined with the intent to provide the most recent literature on the topic. Nonspecific filters to select randomized control were available, although none were used.

\subsection{Study Selection and Data Extraction}

To guarantee the established eligibility criteria, two reviewers (A.F.A.J. and J.A.P.) performed separately the first screen of titles and abstracts of the studies on electronic databases, which investigated all full text of potentially relevant articles. A third reviewer (M.D.A.A.) was consulted to solve any inclusion/exclusion disagreements. Figure 1 shows all the details for the eligibility criteria used for the selection of the articles. Afterward, data extraction was performed by two reviewers together (A.F.A.J. and M.D.A.A.) and the following data were extracted from the selected studies: name of the first author, year of publication, country of origin, aims of the investigation, study population (sample size and age), type of $\mathrm{CP}$, intervention, and main results.

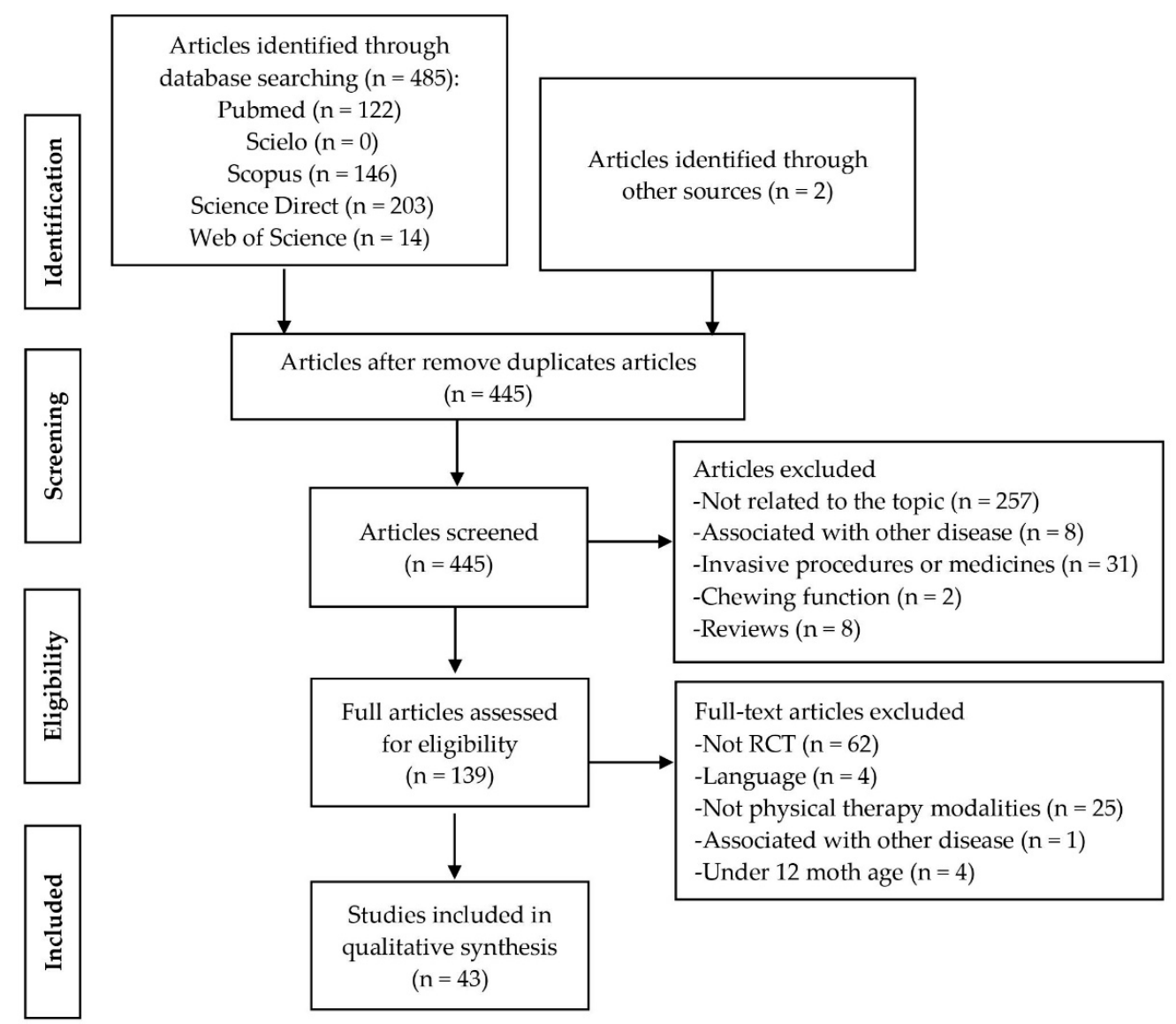

Figure 1. Flowchart of study selection in electronic databases.

\subsection{Risk of Bias}

Methodological quality of the randomized control trials was assessed with the Evidence Project risk of bias tool [11]. This instrument comprises eight items of three different domains, and responses can vary as Yes (rated as 1 ) or No (rated as 0 ) to create a total score $(0-8)$. A higher result represents a lower bias risk.

\section{Results}

The search strategy in the different electronic databases revealed 485 articles, of which 40 studies were duplicates and 43 met the inclusion criteria (Figure 1). From the selected studies, 37 were RCTs and 6 were RCTs protocols. We included the 6 RCT protocols once 
the methodology outcome measures were well established. Supplementary Files 1 and 2 summarize the characteristics of the selected studies.

\subsection{Participants}

In the 43 studies, 1359 participants with different types of CP formed the analyzed population group. Samples from the studies varied between 102 and 6 subjects. Some authors did not reference palsy typography, referring only to CP [12-17]. From the other studies, 12 focused on spastic hemiplegia/paresis, 9 focused on spastic diplegia/paresis, 7 on just spastic CP, 7 investigated unilateral and bilateral spastic CP and 2 studies included subjects with all types of CP [18,19]. The participants were also classified according to the Gross Motor Function Classification System (GMFCS). Most parts of the studies selected participants who were at levels I to III of impairment $(n=23)$. In addition, eight studies classified the sample according to the Manual Ability Classification System (MACS) and included participants with mild levels of limitations (I-III). Only nine studies included individuals in level III to V of GMFCS, while three articles did not classify the sample according to GMFCS or any other scale. Regarding age, the range of analyzed subjects was from nineteen months to twenty-eight years old; however, $95.2 \%$ of studies $(n=40)$ focused their attention on investigating children with $\mathrm{CP}$.

\subsection{Outcomes Measures}

\subsubsection{Variables}

The study revealed many instruments to measure CP's outcomes that we organized according to the International Classification of Functioning, Disability, and Health (ICF) domains (Table 1). The most cited variables were related to gross motor function and hand and arm motor skills, both variables in the activity and participation component of ICF (Table 1). Another variable well cited by the authors was dynamic balance and was related to involuntary movement reaction functions. Personal factors, such as healthrelated quality of life, spasticity in muscle tone functions, gait pattern, and aerobic capacity in exercise tolerance, were also frequently investigated by the authors (Table 1). Some authors assessed functioning and disability using the ICF for children and youth, among others tests that analyze multiple dimensions related to mobility, domestic life, and life habits in general (Table 2).

\subsubsection{Instruments}

We identified 77 instruments to measure the supra cited variables. The instruments more cited were (a) Time Up and Go (TUG), which assesses dynamic balance in involuntary movement reaction function; (b) 6 min walk test (6MWT), which assesses the estimated aerobic capacity in exercise tolerance; (c) Gross Motor Function Measurement (GMFM) scale, version 66, which evaluates changes in gross motor function; (d) Modified Ashworth Scale (MAS), an instrument for spasticity related to muscle tone function; (e) hand-held dynamometer that assesses muscle strength; and (f) Pediatric Evaluation of Disability Inventory (PEDI) to measure functional status in children with CP (Table 1).

The therapeutic interventions in $\mathrm{CP}$ analyzed with the assessment instruments presented were gaming or technology-assisted therapies, which were the most common type of intervention used by the authors [15,20-33], followed by electrotherapy management [12,34-41], and strength training [42-46]. Although less frequently, the studies investigated aerobic training [14-17], hippotherapy [18,47], music therapy [48,49], gait training [50], and aquatic exercise [51]. Two studies focused their attention on evaluating the effectiveness of home-based programs, both involving technology advice: rehabilitation robot [52] and side-alternating whole-body vibration equipment [13]. A few authors investigated areas such as manual therapy [53], respiratory physical therapy [54], and alternative therapies [55]. Finally, [16] analyzed the effect of segmental training in gross motor function, whereas [19] focused their attention on sports-specific fundamental movement skills training. 


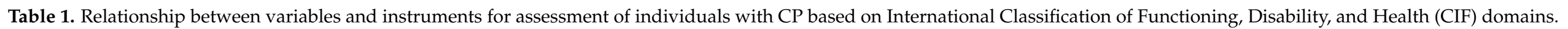

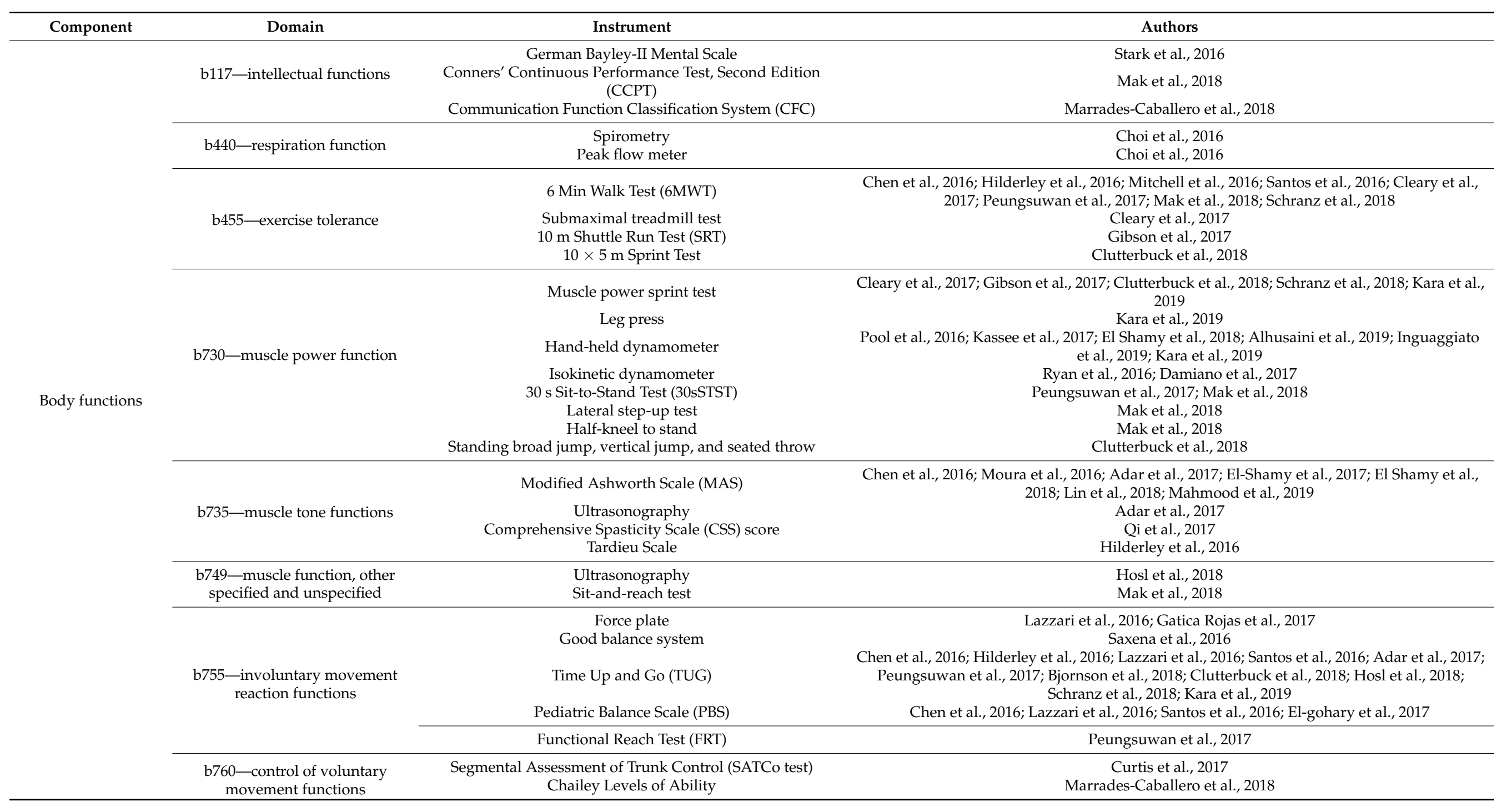


Table 1. Cont.

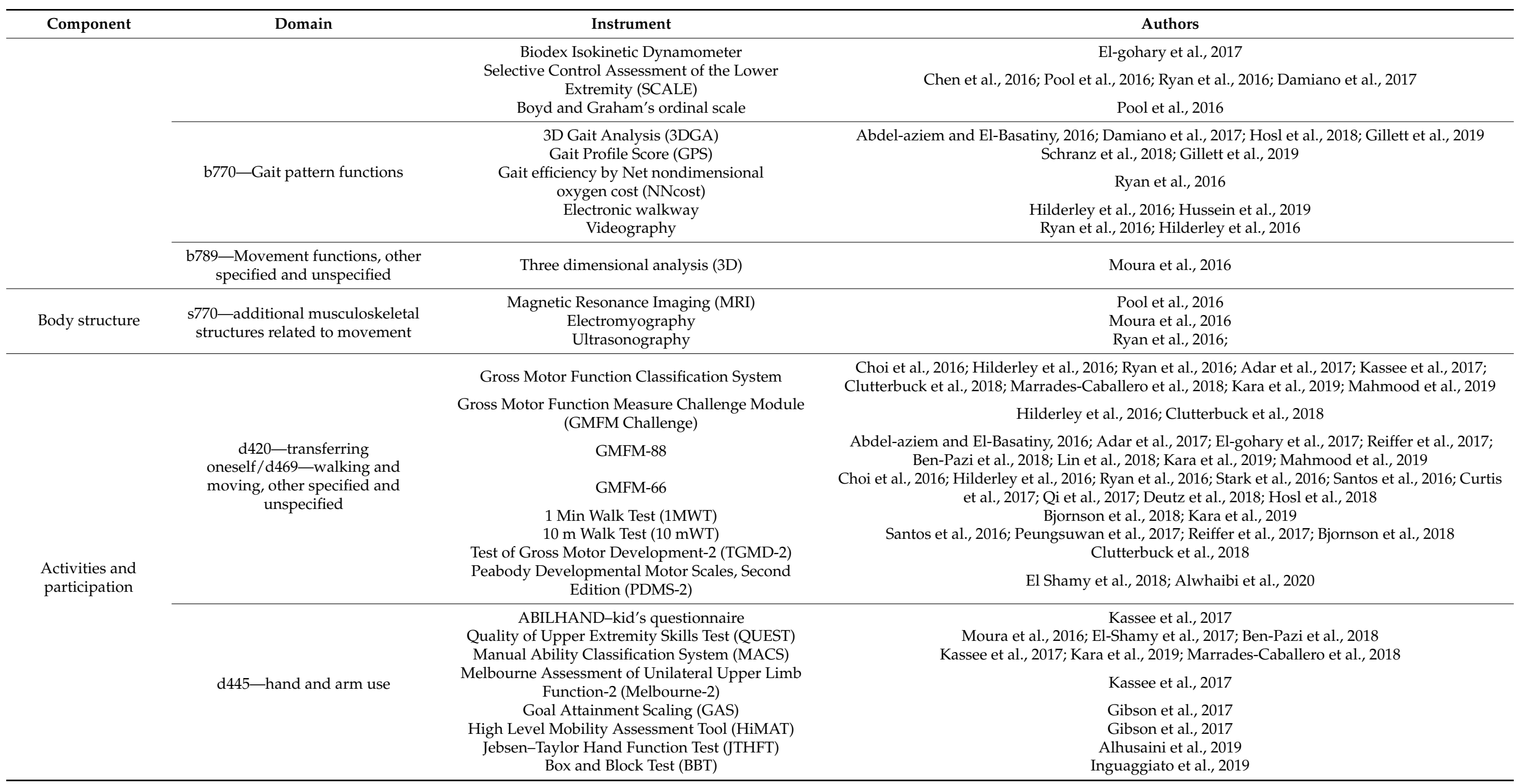


Table 1. Cont.

\begin{tabular}{|c|c|c|c|}
\hline Component & Domain & Instrument & Authors \\
\hline & d450—walk & $\begin{array}{c}\text { Accelerometer } \\
\text { Energy Expenditure Index }\end{array}$ & $\begin{array}{c}\text { Mitchell et al., 2016; Ryan et al., 2016; Cleary et al., 2017; Bjornson et al., } 2018 \\
\text { Schranz et al., } 2018\end{array}$ \\
\hline & d920-recreation and leisure & $\begin{array}{c}\text { Children's Assessment of Participation and Enjoyment } \\
\text { (CAPE) } \\
\text { Preferences of Activities for Children (PAC) }\end{array}$ & $\begin{array}{l}\text { Hilderley et al., 2016; Clutterbuck et al., } 2018 \\
\text { Clutterbuck et al., } 2018\end{array}$ \\
\hline Personal factors & Quality of life & $\begin{array}{c}\text { Pediatric Quality of Life Inventory (PedsQL)-CP } \\
\text { Cerebral Palsy Quality of Life Questionnaire for Children } \\
\text { (CP QOL Child) } \\
\text { Child Health Questionnaire (CHQ 28) } \\
\text { KIDSCREEN-27 parental version } \\
\text { Cerebral Palsy Quality of Life Questionnaire for Adolescents }\end{array}$ & $\begin{array}{c}\text { Adar et al., } 2017 \\
\text { Cleary et al., 2017; Clutterbuck et al., 2018; Mak et al., } 2018 \\
\text { Deutz et al., } 2018 \\
\text { Hilderley et al., 2016; Deutz et al., } 2018 \\
\text { Mak et al., } 2018\end{array}$ \\
\hline
\end{tabular}

Table 2. Relationship between variables and instruments for assessing functioning and disability of individuals with $\mathrm{CP}$ cited in the studies selected.

\begin{tabular}{|c|c|c|}
\hline Variable & Instrument & Authors \\
\hline \multirow{10}{*}{$\begin{array}{l}\text { Functioning } \\
\text { and disability }\end{array}$} & $\begin{array}{l}\text { International Classification of Functioning, Disability and Health-Children } \\
\text { and Youth (ICF-CY) checklist }\end{array}$ & Hsieh et al., 2016; Pool et al., 2016; Curtis et al., 2017 \\
\hline & 28-Item Mobility Questionnaire & Mitchell et al., 2016; Mak et al., 2018 \\
\hline & Assessment of Life Habits (LIFE-H) & Mitchell et al., 2016; Ryan et al., 2016; Bjornson et al., 2018 \\
\hline & Assessment of Motor and Process Skills (AMPS) & Comans et al., 2017 \\
\hline & Canadian Occupational Performance Measure (COPM) & Hilderley et al., 2016; Comans et al., 2017; Clutterbuck et al., 2018 \\
\hline & Functional Mobility Scale (FMS) & Clutterbuck et al., 2018 \\
\hline & Pediatric Outcomes Data Collection Instrument (POCCI) & Damiano et al., 2017 \\
\hline & Patient-Reported Outcomes Measurement Information System (PROMIS) & Bjornson et al., 2018 \\
\hline & Timed Stairs Test (TST) & Schranz et al., 2018 \\
\hline & Wee Functional Independence Measure (WeeFIM) & Adar et al., 2017 \\
\hline
\end{tabular}




\subsection{Risk of Bias}

The mean score of the risk of bias analysis with the Evidence Project tool was 5.88 out of 8 with a standard deviation of 1.31, and scores ranged from 3 to 7 , as Table 3 shows. All the articles satisfactorily reached the items corresponding to the assessment of study design quality (items 1 and 2). Seven studies did not fulfill item 3.

Table 3. Risk of bias analysis with the Evidence Project tool.

\begin{tabular}{|c|c|c|c|c|c|c|c|c|c|}
\hline \multirow[b]{2}{*}{ Study } & Item 1 & Item 2 & Item 3 & Item 4 & Item 5 & Item 6 & Item 7 & Item 8 & \\
\hline & \multicolumn{3}{|c|}{ Study Design } & \multicolumn{3}{|c|}{$\begin{array}{c}\text { Participant } \\
\text { Representativeness }\end{array}$} & \multicolumn{2}{|c|}{$\begin{array}{c}\text { Equivalence of } \\
\text { Comparison Groups }\end{array}$} & Total Score \\
\hline Abdel-aziem (2016) & Yes & Yes & Yes & Yes & No & Yes & Yes & Yes & $7 / 8$ \\
\hline Adar (2017) & Yes & Yes & Yes & Yes & No & Yes & Yes & Yes & $7 / 8$ \\
\hline Alhusaini (2019) & Yes & Yes & Yes & Yes & No & Yes & No & No & $5 / 8$ \\
\hline Benpazi (2018) & Yes & Yes & Yes & Yes & No & Yes & No & No & $5 / 8$ \\
\hline Bjornson (2018) & Yes & Yes & Yes & Yes & No & Yes & No & No & $5 / 8$ \\
\hline Kai Chen (2016) & Yes & Yes & Yes & Yes & No & Yes & Yes & Yes & $7 / 8$ \\
\hline Choi (2016) & Yes & Yes & Yes & Yes & No & Yes & Yes & Yes & $7 / 8$ \\
\hline Cleary (2017) & Yes & Yes & Yes & Yes & No & Yes & No & No & $5 / 8$ \\
\hline Clutterbuck (2018) & Yes & Yes & No & Yes & Yes & Yes & No & No & $5 / 8$ \\
\hline Comans (2017) & Yes & Yes & No & Yes & Yes & No & Yes & Yes & $6 / 8$ \\
\hline Curtis (2017) & Yes & Yes & Yes & Yes & No & Yes & Yes & Yes & $7 / 8$ \\
\hline Damiano (2017) & Yes & Yes & Yes & Yes & No & Yes & Yes & Yes & $7 / 8$ \\
\hline Deutz (2018) & Yes & Yes & Yes & Yes & No & Yes & Yes & Yes & $7 / 8$ \\
\hline El-gohary (2017) & Yes & Yes & Yes & Yes & No & Yes & Yes & Yes & $7 / 8$ \\
\hline El-shamy (2017) & Yes & Yes & Yes & Yes & No & Yes & Yes & Yes & $7 / 8$ \\
\hline El-shamy (2018) & Yes & Yes & Yes & Yes & No & Yes & No & No & $5 / 8$ \\
\hline Gatica Rojas (2017) & Yes & Yes & Yes & Yes & No & Yes & Yes & Yes & $7 / 8$ \\
\hline Gibson (2017) & Yes & Yes & Yes & Yes & No & Yes & No & No & $5 / 8$ \\
\hline Gillett (2019) & Yes & Yes & Yes & Yes & No & Yes & No & No & $5 / 8$ \\
\hline Hilderley (2016) & Yes & Yes & No & Yes & No & Yes & No & No & $4 / 8$ \\
\hline Hosl (2018) & Yes & Yes & Yes & Yes & No & Yes & No & Yes & $6 / 8$ \\
\hline Hsieh (2016) & Yes & Yes & Yes & Yes & No & Yes & No & No & $5 / 8$ \\
\hline Hussein (2019) & Yes & Yes & Yes & Yes & No & Yes & Yes & Yes & $7 / 8$ \\
\hline Inguaggiato (2019) & Yes & Yes & Yes & Yes & No & Yes & No & Yes & $6 / 8$ \\
\hline Kassee (2017) & Yes & Yes & Yes & Yes & No & Yes & No & No & $5 / 8$ \\
\hline Kayakara (2019) & Yes & Yes & Yes & Yes & No & Yes & Yes & Yes & $7 / 8$ \\
\hline Lazzari (2016) & Yes & Yes & Yes & Yes & No & Yes & Yes & Yes & $7 / 8$ \\
\hline Lin (2018) & Yes & Yes & Yes & Yes & No & Yes & Yes & Yes & $7 / 8$ \\
\hline Mahmood (2019) & Yes & Yes & Yes & Yes & No & Yes & Yes & Yes & $7 / 8$ \\
\hline Mak (2018) & Yes & Yes & Yes & Yes & No & Yes & No & Yes & $6 / 8$ \\
\hline Marrades-caballero (2018) & Yes & Yes & Yes & Yes & No & Yes & Yes & Yes & $7 / 8$ \\
\hline Mitchel (2016) & Yes & Yes & Yes & Yes & No & Yes & Yes & Yes & $7 / 8$ \\
\hline Moura (2016) & Yes & Yes & No & Yes & No & No & No & No & $3 / 8$ \\
\hline Peungsuwan (2017) & Yes & Yes & Yes & Yes & No & Yes & Yes & Yes & $7 / 8$ \\
\hline Pool (2016) & Yes & Yes & Yes & Yes & No & Yes & Yes & Yes & $7 / 8$ \\
\hline Qi (2017) & Yes & Yes & Yes & Yes & No & Yes & Yes & No & $6 / 8$ \\
\hline Reem (2020) & Yes & Yes & Yes & Yes & No & Yes & Yes & Yes & $7 / 8$ \\
\hline Reiffer (2017) & Yes & Yes & No & Yes & No & No & No & No & $3 / 8$ \\
\hline Ryan (2016) & Yes & Yes & No & Yes & No & No & No & No & $3 / 8$ \\
\hline Saxena (2016) & Yes & Yes & Yes & Yes & No & Yes & No & No & $5 / 8$ \\
\hline Schranz (2018) & Yes & Yes & Yes & Yes & No & Yes & No & No & $5 / 8$ \\
\hline Stark 2016 & Yes & Yes & Yes & Yes & No & Yes & Yes & Yes & $7 / 8$ \\
\hline Villaltasantos (2019) & Yes & Yes & No & Yes & No & No & No & No & $3 / 8$ \\
\hline
\end{tabular}

Item 1: Cohort. Item 2: Control or comparison group. Item 3: Pre- and post-intervention data. Item 4: Random assignment of participants to the intervention. Item 5: Random selection of participants for assessment. Item 6: Follow-up rate of 80\% or more. Item 7: Comparison group equivalent on sociodemographics. Item 8: Comparison group equivalent at baseline on outcome measures.

In contrast, the participants' representativeness evaluation shows more heterogeneous results. Item 4, which assessed the "random assignment of participants to the intervention", 
was reached by all studies. However, the two articles did not fulfill item 5 ("random selection of participants for assessment"). Five studies did not fulfill item 6 ("follow-up rate of $80 \%$ or more"). Finally, in the equivalence of comparison groups, item 7 was fulfilled by 23 , and item 8 by 25 .

\section{Discussion}

This systematic review aimed to analyze which tools are the most suitable for measurable outcomes in patients with $\mathrm{CP}$ treated with physical therapy and other therapies. It provided an overview of evaluation procedures used in different physical therapy modalities and verification if technological advance has started to be implemented in the process. The present study identified 77 instruments to measure $\mathrm{CP}$ outcomes to analyze physical capacities, functionality, and quality of life adapted to different ages, but mainly designed for children and youth. In addition, according to the results, 21 of the 43 studies used 10 technology-based instruments.

Regarding the instruments used by the authors, when the focus was to analyze the patients' level of functioning and disability, the authors did not indicate a type of instrument that contemplated all aspects of interest. Of 12 tools, the Pediatric Evaluation of Disability Inventory (PEDI) and its variances were the most cited [13,15,16,24,41]. The PEDI tool had its reliability and validity tested in another study, being compared with others instruments such as Pediatric Outcomes Data Collection Instrument (PODCI) and the Child Health Questionnaire (CHQ), which showed higher internal consistency [56]. In addition, the computer adaptive test version (PEDI-CAT) was also an outcome measure that demonstrates strong construct validity and reliability in children with CP [57].

The instruments to assess aerobic fitness, dynamic balance, and spasticity seem to be better established in the literature. To estimate aerobic capacity, the 6 min walk test (6MWT) represents the most preferred test $[14,15,20,41-43,52,55]$. The $6 \mathrm{MWT}$ is used in children with $\mathrm{CP}$ to monitor changes in functional ability, providing representative data with good reproducibility regarding aerobic capacity [58]. In order to assess dynamic balance, the authors only performed three tests and were not developed for children with CP. Time Up and Go test (TUG) was the instrument more widely used [12,15,19,27,29,41-43,45,51,52], probably due to the simplicity of the test administration. To measure spasticity, authors had primarily used the Modified Ashworth Scale (MAS) [25,28,38,40,52,53]; this tool shows a solid, literature-based, inter- and intra-rater agreement, exhibiting a better reliability when measuring upper rather than lower extremities [59].

Additionally, regarding gross motor function, it is possible to observe a large number of studies that used the GMFM scale, versions 88 and $66(n=20)$ (Table 3). Both are effective and useful as outcome measures to detect changes over time in gross motor function in children with $\mathrm{CP}$ undergoing physical therapy [60]. The main differences between the scales are the year of publication and the score calculation and presentation. The original version is the GMFM-88, which provides scores for five dimensions and a total score. The more recent version is called the GMFM-66, which comprises 66 items and provides only a total score. As GMFM-66 is based on an interval scale and accounts for different skills difficulties, it is favored by some authors [61].

Others physical capacities, such as muscle strength, gait, and anaerobic fitness, were also well investigated in the studies selected. The instruments preferred for measuring outcomes for each variable were the hand-held dynamometer [25,33,34,36,37,45], 3D gait analysis [24,29,44,50], and the Muscle Power Sprint Test [14,17,19,43,45]. Similarly, when the studies focused on the assessment of gait, muscle balance, and activity performance, the authors preferred technological resources. For gait analysis, the authors proposed tools based on three-dimensional analysis and videography $[15,24,29,30,38,44,46,50]$. For the assessment of muscle strength, several authors proposed the use of dynamometers $[24,25,33,34,36,37,45,46]$. Muscle activity was measured by electromyography [38], and magnetic resonance imaging [34] and ultrasonography [46,51] were proposed for the assessment of muscle structure and volume. Accelerometers in this review were used in 
four studies to assess activity performance $[14,20,27,46]$, although there are also previous studies in which accelerometry was used for gait analysis [6]. In all the studies that used gait, muscle, balance, and activity performance tools, complementary tools-tests, questionnaires, or clinical observations-were also employed. None of the studies reported their results by using a single assessment tool. As in one study there were several variables, the complementary assessment tools allowed for adjusting the study's objectives and population characteristics. None of the studies that included subjects with severe impairment (GMFCS V) used technology-based assessment tools. Instead, the variables assessed were postural control-related using tools as in [16,49]: (a) SATCo test and Chailey levels of ability; (b) motor skills [48,49]; (c) Quality of Upper Extremity Skills Test and Manual Ability Classification System; and (d) gross motor function [16,18] using PEDI and ICF-CY checklists and cognitive development. Marrades-Caballero et al., 2018 [49] utilized the Communication Function Classification System (CFC).

Of the 43 studies included, only three evaluated young adults; instead, children and adolescents were the focus of $\mathrm{CP}$ investigations. This fact is related to the life expectancy for patients with $\mathrm{CP}$, which is influenced by many aspects, when considering the effects on the severity of physical, cognitive, and sensitive disorders [62]. In individuals with mild impairment, the survival patterns are similar to the general population; for the most severely impaired, however, the mortality by 15 years old is $50 \%$ according to the overall disability score (DISAB) [63].

According to the results of our work, the studies scoring higher $(7 / 8)$ in risk of bias analysis, and those with the lowest scores (3/8) use similar tests, questionnaires, and outcomes measures. Eighty-eight percent of the articles analyzed (38 articles) scored five or more out of eight items, so we can consider them to be clinical trials and protocol studies of good quality and, therefore, outcome measures acceptable for $\mathrm{CP}$ use. The good quality of the studies indicates that the way the instruments were used was probably adequate to achieve the results; however, the analysis as to the adequacy of the instruments used should be done more specifically in future studies. This work covers many articles that might have relevant importance for the clinical management of CP. At the same time, we consider the variability as a limitation because there is more than one assessment of the same indicator and some articles (Table 2) that describe the instruments and methodologies, but are still in the protocol phase and lack results.

Many assessment instruments have the advantage of having different options to adapt to $\mathrm{CP}^{\prime}$ s heterogeneous population. At the same time, they have the limitation that prevents comparison among different studies. Alternatively, we note that few studies introduce technology-based assessment tools, making it also necessary to implement these resources in people with severe impairment (GMFCS V). In the future, it will be of interest to analyze which assessment tools are more sensitive and reliable, and associate these tools with the different levels of GMFCS.

\section{Conclusions}

$\mathrm{CP}$ dysfunctions related to physical capacity, especially gross motor function and motor skills, have drawn the attention of physiotherapy researchers. These factors are the most affected and directly impact the functionality in daily life and the quality of life of children with CP. A large number of instruments have been used in studies to measure the outcomes of physical therapy interventions. Although there is no consensus on the best tool to evaluate most of the variables studied, this systematic review may provide an overview of instrument use by authors in the field of neurorehabilitation.

The use of gaming and technology-assisted therapies in the treatment of $\mathrm{CP}$ has grown in the past years, showing good results in children with different types of CP. This practice can help individuals to adhere to treatment, bringing better results in rehabilitation when compared to conventional physical therapy. 
Supplementary Materials: The following are available online at https:/ / www.mdpi.com/article/ $10.3390 /$ jpm11070604/s1, Table S1-Formal characteristics of the selected studies and main outcomes of the interventions $(n=37)$. Table S2-Formal characteristics of the design of randomized control trials protocols included $(n=6)$.

Author Contributions: Conceptualization, M.D.A.-A. and J.A.P.; methodology, A.F.d.A.J., M.D.A.-A. and J.A.P.; validation, M.D.A.-A. and J.A.P.; formal analysis, A.F.d.A.J., O.F. and A.C.-P.; investigation, A.F.d.A.J. and A.C.-P.; resources, A.F.d.A.J.; data curation, A.F.d.A.J., J.A.P. and M.D.A.-A.; writingoriginal draft preparation, J.A. and A.F.d.A.J.; writing-review and editing, J.A.P., O.F. and M.D.A.-A.; supervision, J.A.P.; project administration, M.D.A.-A. and J.A.P.; funding acquisition, O.F. and J.A.P. All authors have read and agree to the published version of the manuscript.

Funding: The present publication was funded by Fundação Ciência e Tecnologia, IP national support through CHRC (UIDP/04923/2020).

Institutional Review Board Statement: Not applicable.

Informed Consent Statement: Not applicable.

Data Availability Statement: Not applicable.

Conflicts of Interest: Authors declare no conflict of interest.

\section{References}

1. Rosenbaum, P.; Paneth, N.; Leviton, A.; Goldstein, M.; Bax, M. The Definition and Classification of Cerebral Palsy-A report: The definition and classification of cerebral palsy. Dev. Med. Child Neurol. 2007, 49, 1-44.

2. Sadowska, M.; Sarecka-Hujar, B.; Kopyta, I. Cerebral palsy: Current opinions on definition, epidemiology, risk factors, classification and treatment options. Neuropsychiatr. Dis. Treat. 2020, 16, 1505-1518. [CrossRef]

3. Stavsky, M.; Mor, O.; Mastrolia, S.A.; Greenbaum, S.; Than, N.G.; Erez, O. Cerebral palsy-trends in epidemiology and recent development in prenatal mechanisms of disease, treatment, and prevention. Front. Pediatrics 2017, 5, 21. [CrossRef] [PubMed]

4. Novak, I.; Morgan, C.; Adde, L.; Blackman, J.; Boyd, R.N.; Brunstrom-Hernandez, J.; Cioni, G.; Damiano, D.; Darrah, J.; Eliasson, A.-C.; et al. Early, Accurate Diagnosis and Early Intervention in Cerebral Palsy: Advances in Diagnosis and Treatment. JAMA 2017, 171, 897. [CrossRef]

5. Imms, C.; Adair, B. Participation trajectories: Impact of school transitions on children and adolescents with cerebral palsy. Dev. Med. Child Neurol. 2017, 59, 174-182. [CrossRef]

6. Iosa, M.; Marro, T.; Paolucci, S.; Morelli, D. Stability and harmony of gait in children with cerebral palsy. Res. Dev. Disabil. 2012, 33, 129-135. [CrossRef]

7. Ryu, K.; Ali, A.; Kwon, M.; Lee, C.; Kim, Y.; Lee, G.; Kim, J. Effects of assisted aquatic movement and horseback riding therapies on emotion and brain activation in patients with cerebral palsy. J. Phys. Ther. Sci. 2016, 28, 3283-3287. [CrossRef] [PubMed]

8. Obembe, A.O.; Dada, O.; Balogun, A.O.; Ojo, O.W.; Johnson, O.E. Standardized outcome measures for cerebral palsy among physiotherapists in southwestern Nigeria: Awareness, use, barriers, and facilitators. Physiother. Theory Pract. 2019, 35, 1314-1321. [CrossRef] [PubMed]

9. Miller, F.; Neil, M.E.O. Cerebral Palsy; Springer: New York, 2006; p. 3145.

10. Das, S.P.; Ganesh, G.S. Evidence-based Approach to Physical Therapy in Cerebral Palsy. Indian J. Orthop. 2018, 52, 161-169.

11. Kennedy, C.E.; Fonner, V.A.; Armstrong, K.A.; Denison, J.A.; Yeh, P.T.; O'Reilly, K.R.; Sweat, M.D. The Evidence Project risk of bias tool: Assessing study rigor for both randomized and non-randomized intervention studies. Syst. Rev. 2019, 8, 3. [CrossRef]

12. Lazzari, R.D.; Politti, F.; Belina, S.F.; Collange Grecco, L.A.; Santos, C.A.; Dumont, A.J.L.; Lopes, J.B.P.; Cimolin, V.; Galli, M.; Santos Oliveira, C. Effect of Transcranial Direct Current Stimulation Combined With Virtual Reality Training on Balance in Children With Cerebral Palsy: A Randomized, Controlled, Double-Blind, Clinical Trial. J. Mot. Behav. 2017, 49, 329-336. [CrossRef] [PubMed]

13. Stark, C.; Herkenrath, P.; Hollmann, H.; Waltz, S.; Becker, I.; Hoebing, L.; Semler, O.; Hoyer-Kuhn, H.; Duran, I.; Hero, B.; et al. Early vibration assisted physiotherapy in toddlers with cerebral palsy-A randomized controlled pilot trial. J. Musculoskelet. Neuronal Interact. 2016, 16, 183-192.

14. Cleary, S.L.; Taylor, N.F.; Dodd, K.J.; Shields, N. An aerobic exercise program for young people with cerebral palsy in specialist schools: A phase I randomized controlled trial. Dev. Neurorehabilit. 2017, 20, 331-338. [CrossRef] [PubMed]

15. Hilderley, A.J.; Fehlings, D.; Lee, G.W.; Wright, F.V. Comparison of a robotic-assisted gait training program with a program of functional gait training for children with cerebral palsy: Design and methods of a two group randomized controlled cross-over trial. SpringerPlus 2016, 5, 1886. [CrossRef]

16. Curtis, D.J.; Woollacott, M.; Bencke, J.; Lauridsen, H.B.; Saavedra, S.; Bandholm, T.; Sonne-Holm, S. The functional effect of segmental trunk and head control training in moderate-to-severe cerebral palsy: A randomized controlled trial. Dev. Neurorehabilit. 2017, 21, 91-100. [CrossRef] [PubMed] 
17. Gibson, N.; Chappell, A.; Blackmore, A.M.; Morris, S.; Williams, G.; Bear, N.; Allison, G. The effect of a running intervention on running ability and participation in children with cerebral palsy: A randomized controlled trial. Disabil. Rehabil. 2018, 40, 3041-3049. [CrossRef] [PubMed]

18. Hsieh, Y.L.; Yang, C.C.; Sun, S.H.; Chan, S.Y.; Wang, T.H.; Luo, H.J. Effects of hippotherapy on body functions, activities and participation in children with cerebral palsy based on ICF-CY assessments. Disabil. Rehabil. 2017, 39, 1703-1713. [CrossRef] [PubMed]

19. Clutterbuck, G.L.; Auld, M.L.; Johnston, L.M. SPORTS STARS study protocol: A randomised, controlled trial of the effectiveness of a physiotherapist-led modified sport intervention for ambulant school-aged children with cerebral palsy. BMC Pediatrics 2018, 18, 258. [CrossRef]

20. Mitchell, L.E.; Ziviani, J.; Boyd, R.N. A randomized controlled trial of web-based training to increase activity in children with cerebral palsy. Dev. Med. Child Neurol. 2016, 58, 767-773. [CrossRef]

21. Saxena, S.; Rao, B.K.; Senthil, K.D. Short-term balance training with computer-based feedback in children with cerebral palsy: A feasibility and pilot randomized trial. Dev. Neurorehabilit. 2017, 20, 115-120. [CrossRef] [PubMed]

22. Comans, T.; Mihala, G.; Sakzewski, L.; Boyd, R.N.; Scuffham, P. The cost-effectiveness of a web-based multimodal therapy for unilateral cerebral palsy: The Mitii randomized controlled trial. Dev. Med. Child Neurol. 2017, 59, 756-761. [CrossRef]

23. El-gohary, T.M.; Emara, H.A.; Al-Shenqiti, A.; Hegazy, F.A. Biodex balance training versus conventional balance training for children with spastic diplegia. J. Taibah Univ. Med. Sci. 2017, 12, 534-540. [CrossRef]

24. Damiano, D.L.; Stanley, C.J.; Ohlrich, L.; Alter, K.E. Task-Specific and Functional Effects of Speed-Focused Elliptical or MotorAssisted Cycle Training in Children with Bilateral Cerebral Palsy: Randomized Clinical Trial. Neurorehabilit. Neural Repair 2017, 31, 736-745. [CrossRef]

25. El-Shamy, S.M. Efficacy of Armeo ${ }^{\circledR}$ Robotic Therapy Versus Conventional Therapy on Upper Limb Function in Children With Hemiplegic Cerebral Palsy. Am. J. Phys. Med. Rehabil. 2018, 97, 164-169. [CrossRef]

26. Gatica-Rojas, V.; Méndez-Rebolledo, G.; Guzman-Muñoz, E.; Soto-Poblete, A.; Cartes-Velásquez, R.; Elgueta-Cancino, E.; Cofré Lizama, L.E. Does Nintendo Wii Balance Board improve standing balance? A randomized controlled trial in children with cerebral palsy. Eur. J. Phys. Rehabil. Med. 2017, 53, 535-544.

27. Bjornson, K.F.; Moreau, N.; Bodkin, A.W. Short-burst interval treadmill training walking capacity and performance in cerebral palsy: A pilot study. Dev. Neurorehabilit. 2019, 22, 126-133. [CrossRef] [PubMed]

28. El-Shamy, S.M. Effects of Antigravity Treadmill Training on Gait, Balance, and Fall Risk in Children With Diplegic Cerebral Palsy. Am. J. Phys. Med. Rehabil. 2017, 96, 809-815. [CrossRef] [PubMed]

29. Hösl, M.; Böhm, H.; Eck, J.; Döderlein, L.; Arampatzis, A. Effects of backward-downhill treadmill training versus manual static plantarflexor stretching on muscle-joint pathology and function in children with spastic Cerebral Palsy. Gait Posture 2018, 65, 121-128. [CrossRef] [PubMed]

30. Hussein, Z.A.; Salem, I.A.; Ali, M.S. Effect of simultaneous proprioceptive-visual feedback on gait of children with spastic diplegic cerebral palsy. J. Musculoskelet. Neuronal Interact. 2019, 19, 500-506. [PubMed]

31. Alwhaibi, R.; Alsakhawi, R.; ElKholi, S. Effects of auditovisual feedback on eye-hand coordination in children with cerebral palsy. Res. Dev. Disabil. 2020, 101, 103635. [CrossRef] [PubMed]

32. Ammann-Reiffer, C.; Bastiaenen, C.H.G.G.; Meyer-Heim, A.D.; van Hedel, H.J.A.A. Effectiveness of robot-assisted gait training in children with cerebral palsy: A bicenter, pragmatic, randomized, cross-over trial (PeLoGAIT). BMC Pediatrics 2017, 17, 64. [CrossRef]

33. Kassee, C.; Hunt, C.; Holmes, M.W.R.; Lloyd, M. Home-based Nintendo Wii training to improve upper-limb function in children ages 7 to 12 with spastic hemiplegic cerebral palsy. J. Pediatric Rehabil. Med. 2017, 10, 145-154. [CrossRef] [PubMed]

34. Pool, D.; Elliott, C.; Bear, N.; Donnelly, C.J.; Davis, C.; Stannage, K.; Valentine, J. Neuromuscular electrical stimulation-assisted gait increases muscle strength and volume in children with unilateral spastic cerebral palsy. Dev. Med. Child Neurol. 2016, 58, 492-501. [CrossRef]

35. Qi, Y.-C.C.; Niu, X.-L.L.; Gao, Y.-R.R.; Wang, H.-B.B.; Hu, M.; Dong, L.-P.P.; Li, Y.-Z.Z. Therapeutic Effect Evaluation of Neuromuscular Electrical Stimulation With or Without Strengthening Exercise on Spastic Cerebral Palsy. Clin. Pediatrics 2018, 57, 580-583. [CrossRef] [PubMed]

36. Alhusaini, A.A.; Fallatah, S.; Melam, G.R.; Buragadda, S. Efficacy of transcutaneous electrical nerve stimulation combined with therapeutic exercise on hand function in children with hemiplegic cerebral palsy. Somatosens. Mot. Res. 2019, 36, 49-55. [CrossRef] [PubMed]

37. Inguaggiato, E.; Bolognini, N.; Fiori, S.; Cioni, G. Transcranial direct current stimulation (tDCS) in unilateral cerebral palsy: A pilot study of motor effect. Neural Plast. 2019, 2019, 2184398. [CrossRef] [PubMed]

38. Moura, R.C.F.; Santos, C.A.; Grecco, L.A.C.; Lazzari, R.D.; Dumont, A.J.L.; Duarte NC de, A.; Braun, L.A.; Lopes, J.B.P.; Santos, L.A.D.; Rodrigues, E.L.S.; et al. Transcranial direct current stimulation combined with upper limb functional training in children with spastic, hemiparetic cerebral palsy: Study protocol for a randomized controlled trial. Trials 2016, 17, 405. [CrossRef]

39. Contreras Campos, M.E.; Rodriguez-Cervantes, N.; Reza-Lopez, S.; Avila-Esparza, M.; Chavez-Corral, D.V.; Levario-Carrillo, M. Body composition and newborn birthweight in pregnancies of adolescent and mature women. Matern. Child Nutr. 2015, 11, 164-172. [CrossRef] 
40. Lin, Y.; Wang, G.; Wang, B. Rehabilitation treatment of spastic cerebral palsy with radial extracorporeal shock wave therapy and rehabilitation therapy. Medicine 2018, 97, e13828. [CrossRef]

41. Santos, L.V.; Lopes, J.B.P.; Duarte, N.A.C.; Galli, M.; Grecco, L.A.C.; Oliveira, C.S.; Villalta Santos, L.; Benite Palma Lopes, J.; Almeida Carvalho Duarte, N.; Galli, M.; et al. Effect of Anodic tDCS Over Motor Cortex Versus Cerebellum in Cerebral Palsy: A Study Protocol. Pediatric Phys. Ther. 2019, 31, 301-305. [CrossRef] [PubMed]

42. Peungsuwan, P.; Parasin, P.; Siritaratiwat, W.; Prasertnu, J.; Yamauchi, J. Effects of Combined Exercise Training on Functional Performance in Children With Cerebral Palsy: A Randomized-Controlled Study. Pediatric Phys. Ther. 2017, 29, 39-46. [CrossRef] [PubMed]

43. Schranz, C.; Kruse, A.; Belohlavek, T.; Steinwender, G.; Tilp, M.; Pieber, T.; Svehlik, M. Does Home-Based Progressive Resistance or High-Intensity Circuit Training Improve Strength, Function, Activity or Participation in Children With Cerebral Palsy? Arch. Phys. Med. Rehabil. 2018, 99, 2457-2464.e4. [CrossRef] [PubMed]

44. Gillett, J.G.; Lichtwark, G.A.; Boyd, R.N.; Carty, C.P.; Barber, L.A. The effect of combined functional anaerobic and strength training on treadmill gait kinematics and kinetics in ambulatory young adults with cerebral palsy. Gait Posture 2019, 70, 323-329. [CrossRef]

45. Kara, O.K.; Livanelioglu, A.; Yardimci, B.N.; Soylu, A.R.; Kaya Kara, O.; Livanelioglu, A.; Yardımc1, B.N.; Soylu, A.R. The Effects of Functional Progressive Strength and Power Training in Children With Unilateral Cerebral Palsy. Pediatric Phys. Ther. 2019, 31, 286-295. [CrossRef]

46. Ryan, J.M.; Theis, N.; Kilbride, C.; Baltzopoulos, V.; Waugh, C.; Shortland, A.; Lavelle, G.; Noorkoiv, M.; Levin, W.; Korff, T. Strength Training for Adolescents with cerebral palsy (STAR): Study protocol of a randomised controlled trial to determine the feasibility, acceptability and efficacy of resistance training for adolescents with cerebral palsy. BMJ Open 2016, 6, e012839. [CrossRef] [PubMed]

47. Deutz, U.; Heussen, N.; Weigt-Usinger, K.; Leiz, S.; Raabe, C.; Polster, T.; Daniela, S.; Moll, C.; Lücke, T.; Krägeloh-Mann, I.; et al. Impact of Hippotherapy on Gross Motor Function and Quality of Life in Children with Bilateral Cerebral Palsy: A Randomized Open-Label Crossover Study. Neuropediatrics 2018, 49, 185-192. [CrossRef]

48. Ben-Pazi, H.; Aran, A.; Pandyan, A.; Gelkop, N.; Ginsberg, G.; Pollak, Y.; Elnatan, D. Auditory stimulation improves motor function and caretaker burden in children with cerebral palsy-A randomized double blind study. PLoS ONE 2018, 13, e0208792. [CrossRef] [PubMed]

49. Marrades-Caballero, E.; Santonja-Medina, C.S.; Sanz-Mengibar, J.M.; Santonja-Medina, F. Neurologic music therapy in upper-limb rehabilitation in children with severe bilateral cerebral palsy: A randomized controlled trial. Eur. J. Phys. Rehabil. Med. 2018, 54, 866-872. [CrossRef]

50. Abdel-Aziem, A.A.; El-Basatiny, H.M.Y. Effectiveness of backward walking training on walking ability in children with hemiparetic cerebral palsy: A randomized controlled trial. Clin. Rehabil. 2017, 31, 790-797. [CrossRef] [PubMed]

51. Adar, S.; Dündar, Ü.; Demirda, Ü.S.; Ulaşl1, A.M.; Toktaş, H.; Solak, Ö. The effect of aquatic exercise on spasticity, quality of life, and motor function in cerebral palsy. Turk. Fiz. Tip Rehabil. Derg. 2017, 63, 239-248. [CrossRef]

52. Chen, K.; Wu, Y.-N.; Ren, Y.; Liu, L.; Gaebler-Spira, D.; Tankard, K.; Lee, J.; Song, W.; Wang, M.; Zhang, L.-Q. Home-Based Versus Laboratory-Based Robotic Ankle Training for Children With Cerebral Palsy: A Pilot Randomized Comparative Trial. Arch. Phys. Med. Rehabil. 2016, 97, 1237-1243. [CrossRef]

53. Mahmood, Q.; Habibullah, S.; Babur, M.N. The effects of traditional massage on spasticity of children with cerebral palsy: A randomized controlled trial. JPMA 2020, 70, 809-814. [CrossRef]

54. Choi, J.Y.; Rha, D.; Park, E.S. Change in Pulmonary Function after Incentive Spirometer Exercise in Children with Spastic Cerebral Palsy: A Randomized Controlled Study. Yonsei Med. J. 2016, 57, 769-775. [CrossRef] [PubMed]

55. Mak, C.; Whittingham, K.; Cunnington, R.; Boyd, R.N. Effect of mindfulness yoga programme MiYoga on attention, behaviour, and physical outcomes in cerebral palsy: A randomized controlled trial. Dev. Med. child Neurol. 2018, 60, 922-932. [CrossRef] [PubMed]

56. McCarthy, M.L.; Silberstein, C.E.; Atkins, E.A.; Harryman, S.E.; Sponseller, P.D.; Hadley-Miller, N.A. Comparing reliability and validity of pediatric instruments for measuring health and well-being of children with spastic cerebral palsy. Dev. Med. Child Neurol. 2002, 44, 468-476. [CrossRef] [PubMed]

57. Shore, B.J.; Allar, B.G.; Miller, P.E.; Matheney, T.H.; Snyder, B.D.; Fragala-Pinkham, M. Measuring the Reliability and Construct Validity of the Pediatric Evaluation of Disability Inventory-Computer Adaptive Test (PEDI-CAT) in Children With Cerebral Palsy. Arch. Phys. Med. Rehabil. 2019, 100, 45-51. [CrossRef]

58. Fitzgerald, D.; Hickey, C.; Delahunt, E.; Walsh, M.; O’Brien, T. Six-minute walk test in children with spastic cerebral palsy and children developing typically. Pediatric Phys. Ther. 2016, 28, 192-199. [CrossRef]

59. Meseguer-Henarejos, A.B.; Sănchez-Meca, J.; López-Pina, J.A.; Carles-Hernăndez, R. Inter-and intra-rater reliability of the Modified Ashworth Scale: A systematic review and meta-analysis. Eur. J. Phys. Rehabil. Med. 2018, 54, 576-590.

60. Alotaibi, M.; Long, T.; Kennedy, E.; Bavishi, S. The efficacy of GMFM-88 and GMFM-66 to detect changes in gross motor function in children with cerebral palsy (CP): A literature review. Disabil. Rehabil. 2014, 36, 617-627. [CrossRef]

61. Ko, J. Sensitivity to functional improvements of GMFM-88, GMFM-66, and pedi mobility scores in young children with cerebral palsy. Percept. Mot. Skills 2014, 119, 305-319. [CrossRef] 
62. Rebel, M.F.; Rodrigues, R.F.; Araújo AP de, Q.C.; Corrêa, C.L. Motor Prognosis and Current Perspectives in Cerebral Palsy. J. Hum. Growth Dev. 2010, 20, 342-350. [CrossRef]

63. Blair, E.; Langdon, K.; Mcintyre, S.; Lawrence, D.; Watson, L. Survival and Mortality in Cerebral Palsy: Observations to the Sixth Decade from a Data Linkage Study of a Total Population Register and National Death Index. BMC Neurology. 2019, $19,1-11$. [CrossRef] [PubMed] 